\title{
The effect of aqueous extract of Prunus dulcis on tibial bone healing in the rabbit
}

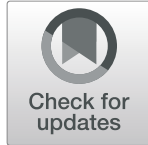

\author{
Nima Anaraki ${ }^{1 \dagger}$, Amir Hossein Beyraghi ${ }^{1 \dagger}$, Abbas Raisi $^{i^{*}}$ (D), Farshid Davoodi ${ }^{1,2^{*}}$, Ghasem Farjanikish ${ }^{3}$ and \\ Amin Bigham Sadegh ${ }^{4}$
}

\begin{abstract}
Background: Bone fractures are medical emergencies that require prompt intervention to help return bone to its normal function. Various methods and treatments have been utilized to increase the speed and efficiency of bone repair. This study aimed to investigate the treatment effects of Prunus dulcis aqueous extract on tibial bone healing in rabbits.
\end{abstract}

Methods: All animals were distributed in five groups with six rats in each group, including the sham group, the control group in which tibial lesion was made and received distilled water, treatment groups with $150 \mathrm{mg} \mathrm{kg}^{-1}$, $300 \mathrm{mg} \mathrm{kg}^{-1}$ doses of Prunus dulcis extract, and osteocare treated group. Biochemical blood factors including calcium, phosphorus, and alkaline phosphatase (on days 0, 10, 30, and 50), biomarkers of oxidative stress such as GPx, CAT, and MDA (on days 10 and 30), radiological evaluation, histopathological parameters, and osteocalcin immunohistochemical expression were assessed.

Results: The data showed calcium levels in the treatment groups increased significantly from day 10 to day 50, respectively, and blood phosphorus levels decreased from day 10 to day 50 in the treatment groups. Alkaline phosphatase initially increased and then decreased in treatment groups. In the treatment groups, GPx and CAT levels significantly increased, and the serum amount of MDA reduced. The best antioxidant results were related to the extract-treated group with a higher dose. Radiographic score was significantly higher in the treatment groups than the control group on day 30. Based on the pathological findings, the healing occurred faster in the extract-treated group with a higher dose. Osteocalcin expression was significantly higher in the control group than that in the treatment groups.

Conclusions: Treatment with Prunus dulcis extract with a dosage of $300 \mathrm{mg} / \mathrm{kg}$ accelerated tibial bone healing in rabbits.

Keywords: Bone regeneration, Fracture healing, Prunus dulcis, Almond, Bone healing, Tibial fracture

\section{Introduction}

Bone is a tissue whose injuries have been reported frequently, and bone injuries can severely affect the quality of life [1]. Orthopedic surgeons constantly confront several challenges when curing the fractures, including malunion, nonunion, and delayed union bone fractures [2].

\footnotetext{
*Correspondence: raisi.a@lu.ac.ir; Farshiddavoodi620@yahoo.com

${ }^{\dagger}$ Nima Anaraki and Amir Hosein Beiraghi contributed equally to this work. 'Department of Clinical Sciences, Faculty of Veterinary Medicine, Lorestan University, Khorramabad, Iran

Full list of author information is available at the end of the article
}

Good reduction and alignment lead to bone healing. However, in some cases, bone grafts are employed to help fast healing with better results [3]. There are various types of bone grafts, such as autografts, allografts, and xenografts. Autografts are defined as gold standards in literature. The most common complication of autografts is disorders of the donor site. Application of the allografts is also limited owing to host immune responses [4]. Bone healing possesses three phases, including the inflammatory stage, repair stage, and remodeling [5]. The bone healing process is regulated by plenty of

C C The Author(s). 2021 Open Access This article is licensed under a Creative Commons Attribution 4.0 International License, which permits use, sharing, adaptation, distribution and reproduction in any medium or format, as long as you give appropriate credit to the original author(s) and the source, provide a link to the Creative Commons licence, and indicate if changes were made. The images or other third party material in this article are included in the article's Creative Commons licence, unless indicated otherwise in a credit line to the material. If material is not included in the article's Creative Commons licence and your intended use is not permitted by statutory regulation or exceeds the permitted use, you will need to obtain permission directly from the copyright holder. To view a copy of this licence, visit http://creativecommons.org/licenses/by/4.0/ The Creative Commons Public Domain Dedication waiver (http://creativecommons.org/publicdomain/zero/1.0/) applies to the data made available in this article, unless otherwise stated in a credit line to the data. 
agents such as vitamin $\mathrm{D}$, calcitonin hormone, plateletderived growth factors, fibroblast growth factor, and alkaline phosphate level [6].

The use of herbs to treat diseases in humans and animals is growing in many countries [7]. According to the World Health Organization (WHO), about $80 \%$ of people worldwide trust traditional medicine and the use of alternative and complementary medicine, including herbal extracts [8]. Almond, with the scientific name of Prunus dulcis, is a plant native to Iran and the Middle East. This tree is now grown in many countries with various climates [9]. Prunus dulcis is rich in lipids, proteins, fiber, and other minerals. Moreover, like other plant compounds, Prunus dulcis has several antioxidant compounds, such as benzoic acid and flavonoids [10]. Plenty of benefits for the body health were described owing to Prunus dulcis consumption in the previous studies such as balancing the level of serum lipid and glucose, protective effects in cardiovascular disorders, obesity, and diabetes [11]. Evaluating the mineral composition of Prunus dulcis revealed that calcium, phosphorus, potassium, and magnesium are the most important minerals existing in the extract [11].

The present study was aimed to examine the protective effects of Prunus dulcis aqueous extract in improving bone healing in a rabbit model.

\section{Material and methods}

\section{Preparation of aqueous extract of Prunus dulcis}

To prepare the aqueous extract of Prunus dulcis (almond), the Prunus dulcis were completely dried and powdered. Then, 100 grams of the prepared powder was added to $1 \mathrm{~L}$ of boiling water and heated for $10 \mathrm{~min}$. The resulting solution was kept on a shaker for $48 \mathrm{~h}$. The solution was then passed through a filter three times and put in an oven with $37{ }^{\circ} \mathrm{C}$ temperature to be concentrated. The resulting extract was transferred to a freezer with a temperature of $-20{ }^{\circ} \mathrm{C}$ and kept in the freezer until being used in experiments. Afterward, it was dissolved in sterile distilled water according to the desired dose. Prepared samples of Prunus dulcis extract were analyzed using the gas chromatography-mass spectrometry (GC-MS) method for determining the number of different substances available in the extract at the Central Laboratory of Lorestan University. The result of the GC-MS is represented in Table 1.

\section{Animals and groups}

In the present study, 30 albino New Zealand adult male rabbits with an average age of 7-8 months and a weight range of $2.5-3 \mathrm{~kg}$ were utilized. The animal ethics committee approved all the experiments within this study. All rabbits were housed in appropriate standard cages with a temperature of $26 \pm 0.5{ }^{\circ} \mathrm{C}$ and humidity of $55 \pm$
Table 1 Gas chromatography-mass spectrometry (GC-MS) of Prunus Dulcis

\begin{tabular}{ll}
\hline Compound & Percent \\
\hline Benzene alcohol & 38.82 \\
Benzoic acid & 9.98 \\
Propanediol & 9.54 \\
Butanediol & 6.73 \\
Pentanol-3-methyl-2 & 5.36 \\
Geranyl acetate & 5.22 \\
Phenyl ethyl alcohol & 1.65 \\
Hexadecanoic acid & 1.11 \\
Benzyl acetate & 0.98 \\
Terpinolene & 0.89 \\
Eicosane & 0.87 \\
Thymol & 0.72 \\
Carvacrol & 0.57 \\
\hline
\end{tabular}

0.4\%. All animals were fed with commercial rabbit food and water ad libitum and received human care according to Institutional Animal Care guidelines. All rabbits were randomly divided into five groups, with six rats in each group as follows:

Group 1: No surgical procedure was done, and rabbits received a daily oral gavage of the extract with a dosage of $200 \mathrm{mg} / \mathrm{kg}$ (sham group).

Group 2: Tibial lesion was made, and daily oral gavage of distilled water was performed (control group).

Group 3: Tibial lesion was made, and animals received a daily oral gavage of Prunus dulcis extract with a dosage of $150 \mathrm{mg} / \mathrm{kg}$ (PDE 150).

Group 4: Tibial lesion was made, and animals received a daily oral gavage of Prunus dulcis extract with a dosage of $300 \mathrm{mg} / \mathrm{kg}$ (PDE 300).

Group 5: Tibial lesion was induced surgically, and a daily oral gavage of Osteocare syrup (1 ml per day) (VITABIOTICS, London, UK) was performed (OC).

\section{Surgical procedure}

Rabbits were anesthetized using a combination of ketamine hydrochloride $(25 \mathrm{mg} / \mathrm{kg}$, KETASET, Zoetis, NJ, USA) and xylazine (Dutch Farm International, The Netherlands). Rabbits received intravenous cefazoline (20 mg/kg, iv, marginal ear vein) as a prophylactic antibiotic 30 min before surgical procedures. After induction of anesthesia, the left hindlimb of the rabbits was shaved and disinfected using betadine scrub $7.5 \%$. A $3-\mathrm{cm}$ incision was made on the left hindlimb using a scalpel blade No. 10 to access the tibial bone. Regional muscles covering the tibia were precisely incised using scissors, and the tibia was exposed. A 5-ml hole was created on the 
tibial bone [12], and after cleaning the surgical site and washing the site with sterile normal saline, the muscles were sutured (VICRYL,1-0), and the skin was sutured with suture materials (NYLON, 1-0). After the operation, the rabbits in each group were returned to certain cages and kept separately. All animals received intramuscular cefazolin $(20 \mathrm{mg} / \mathrm{kg})$ for 3 days, and the surgical site was examined daily for swelling and infections. No evidence of surgical related complications and infections was observed a week following surgery. The rabbits were kept for 50 days following surgery and got daily oral gavage, based on the treatment groups. Eventually, the rabbits were euthanized using an overdosage of sodium thiopental $(200 \mathrm{mg} / \mathrm{kg})$, and bone samples were taken and were fixed in $10 \%$ formalin buffer solution. Samples fixed in formalin were sent to the pathology laboratory of Lorestan University for histopathological evaluation.

\section{Biochemical analysis of blood samples}

Blood samples were taken on days 0 (before surgery), 10, 30 , and 50 to examine the healing process among different experimental groups of the study. The samples were taken from the marginal ear vein of rabbits and were centrifuged at $5000 \mathrm{rpm}$ for ten minutes to separate the serum. Afterward, serum samples were stored in a freezer at $-20{ }^{\circ} \mathrm{C}$ until being used in subsequent experiments. To measure calcium, phosphorus, and alkaline phosphatase, Biosystems kits (Barcelona, Spain) were employed according to the manufacturer's protocols.

\section{Blood calcium measurement}

Serum calcium was measured using the Arsenazo III enzymatic method. In this method, the blood serum reacts with the Arsenazo enzyme and forms a color solution as a product. Blood calcium was then measured at $650 \mathrm{~nm}$ using a spectrophotometer.

\section{Blood phosphorus measurement}

The enzymatic method of Phosphomolybdate in an acidic medium was employed to measure blood phosphorus. The product of this reaction is molybdenum blue, which was detected in a spectrophotometer with a wavelength of $660 \mathrm{~nm}$, and the amount of phosphorus was calculated according to the kit protocol.

\section{Alkaline phosphatase measurement}

Since the alkaline phosphatase enzyme does not have a specific substrate, various methods were employed in previous studies to measure this enzyme. Herein pNitrophenyl Phosphate was utilized as a substrate. pNitrophenyl Phosphate reacts with Diethylamine (DEA) and produces a colored agent named p-nitrophenol. pnitrophenol is measured in the $409 \mathrm{~nm}$ using a spectrophotometer, which is directly related to alkaline phosphatase activity.

\section{Oxidative damage assessment}

Glutathione peroxidase (GPx) and catalase (CAT) enzymes and the amount of malondialdehyde (MDA) in the serum samples were examined using Asan biochemical kits (Khorramabad, Iran). All methods were carried out based on the protocols described by the manufacturer.

\section{Radiographic assessment}

Radiographs were taken on days 10,30 , and 50 to evaluate the tibial bone healing process. The modified Lane and Sandhu method was employed to score bone radiographs from 0 to 4 grades as follows: score 0 , no sign of bone formation; score 1: bone formation with $25 \%$ defect filling; score 2: bone formation with $50 \%$ defect filling; score 3: bone formation with $75 \%$ defect filling; score 4: bone formation with $100 \%$ defect filling [13].

\section{Histopathological evaluation}

For histopathological evaluation, following the samples' fixation in $10 \%$ formalin buffer solution, they were placed in $15 \%$ nitric acid for $48 \mathrm{~h}$ to absorb calcium from the samples. Subsequently, tissue samples were placed in the Auto-technicon Tissue Processor machine (NY, USA), and dehydration and transparency of samples were automatically performed. Then, tissue samples were immersed in paraffin, and blocks were prepared. A rotary microtome was employed to make $4-5 \mu \mathrm{m}$ sections from the tissue blocks. Provided sections with specified thickness were mounted on microscopic slides, and the hematoxylin and eosin (H\&E) method was employed to stain the slides. Afterward, a skilled pathologist evaluated the slides using a light microscope with different magnifications. All slides were assessed and graded for histopathological parameters, including fibroblasts/fibrocytes, chondroblasts/chondrocytes, osteoblasts/osteocytes, osteoclast, inflammatory cells, vessels, woven bone, and lamellar bone.

\section{Immunohistochemical evaluations}

Prepared tissue blocks were deparaffinized and hydrated. Then, immunohistochemistry staining protocol was performed based on previous studies [14]. In the present study, osteocalcin monoclonal antibody (Ab13420, Abcam, Cambridge, UK) was used to detect osteoblasts and bone formation in different experimental study groups.

\section{Statistical analysis}

Statistical analysis of the data was performed using SPSS software (IBM SPSS Statistics version. 22). A one-way 
ANOVA test was used to compare biochemical parameters, oxidative stress biomarkers, and pathological indicators, and a $\mathrm{p}$ value less than $0.05(p \leq 0.05)$ was considered statistically significant.

\section{Result}

\section{Blood biochemical parameters}

Figure 1 represents the experimental data on calcium, phosphorus, and alkaline phosphatase. Figure 1a shows data regarding blood calcium levels in different study groups on days $0,10,30$, and 50 . According to results on day 10 in all groups except for the control group, the blood calcium level was reduced. In all treatment groups, blood calcium levels increased on day 30 and continued to increase till day 50. Based on the graphs, treatment with PDE 300 and osteocare significantly reduced calcium level on day 10 compared to the control group $(P<0.05)$. Treatment with Prunus dulcis extract with $300 \mathrm{mg} / \mathrm{kg}$ dosage significantly increased calcium level in comparison to the control group $(P<0.05)$.

The results obtained from the preliminary analysis of phosphorus are presented in Fig. 1b. There was a significant difference in serum phosphorus levels between the control group and the sham group on days 30 and $50(P$ $<0.05$ ). On day 10 , a significant difference was observed in the amount of phosphorus in the PDE 300 and OC groups compared to the control group $(P<0.05)$. On day 30 , treatment with osteocare remarkably increased the level of phosphorus compared to both groups treated with PD extract $(P<0.05)$, but no significant difference was observed between the treatment groups and the control group $(P>0.05)$. The amount of phosphorus notably decreased in all treatment groups compared to the control group on day $50(P<0.05)$. Overall, on day 10 in all groups, except for the control group there was an increment in the level of phosphorus, and on day 30, phosphorus level was reduced in all groups except for the control and the OC group.

As shown in Fig. 1c, levels of alkaline phosphatase in the control group were remarkably higher than that in the sham group on days 10,30 , and $50(P<0.05)$. On day 10 , no significant difference was observed between the treatment groups and the control group $(P>0.05)$. On day 10 , no significant difference was observed between the treatment groups and the control group $(P>0.05)$. On day 30 , levels of alkaline phosphatase were significantly lower in the PDE 300 and OC groups in comparison to the PDE 150 group $(P<0.05)$. On day 50 , in all treatment groups, level of the alkaline phosphatase was notably reduced compared to the control group $(P<0.05)$.

\section{Oxidative damage results}

Figure 2a presents the results obtained from the preliminary analysis of MDA. As can be seen from the graph, on days 10 and 30, there was a significant difference between extract-treated groups and the control group $(P<$ $0.05)$. PDE 300 group remarkably reduced the MDA level compared to the PDE 150 group on day $10(P<$ 0.05). Levels of MDA in the PDE 300 group were significantly lower than that in the OC group both on days 10 and $30(P<0.05)$.

Figure $2 \mathrm{~b}$ shows GPx levels in different study groups on days 10 and 30. A significant difference was observed in all treatment groups compared to the control group on days 10 and $30(P<0.05)$. Treatment with PDE 300 notably increased the level of GPx compared to the PDE 150 and $\mathrm{OC}$ groups $(P<0.05)$. There was a significant difference between the OC group and the PDE 150 group on day $10(P<0.05)$.

Figure 2c indicates the catalase activity. All treatment groups had a significant difference with the control group on days 10 and $30(P<0.05)$. In the PDE 300 group level of CAT was higher than that in the PDE 150 and the OC groups on day $10(P<0.05)$.

\section{Radiographic findings}

Figure 3 represents radiographs of tibial bone on days 10, 30, and 50 in various groups. Table 2 indicates the radiographic scores of the tibial bone regeneration in different groups. As can be seen from the table, on day 10 no significant difference was observed between the treatment groups and the control group $(P>0.05)$. On day 30 , a significant difference was observed between all treatment groups and the control group $(P<0.05)$. On day 50 , the difference was not significant between the treatment groups and the control group $(P>0.05)$.

\section{Histopathological results}

Histopathological slides of the H\&E staining method are indicated in Fig. 4. According to Fig. 4A, in the control group, which did not receive any treatment, a large number of woven bones were observed at the site of repair, and a low reconstruction was observed. Furthermore, large amounts of new vessels were observed, and the amount of hyaline cartilage was lower than the other groups. Weak connective tissue and many singlenucleated inflammatory cells were detected. Figure $4 \mathrm{~B}$ presents the histopathology of the PDE 150 group. In this group, the formation of primary osteocytes, hyaline cartilage, haversian canals, dense connective tissue was observed at the fracture site. Histopathological slide of the $\mathrm{OC}$ group is shown in Fig. 4C. In this treatment group, reconstruction of hyaline cartilage and dense connective tissue was observed simultaneously. Figure 4D indicates a pathological slide regarding the PDE 300 group. New bone formation, very soft connective tissue, formation and regeneration of Haversian canals, and 

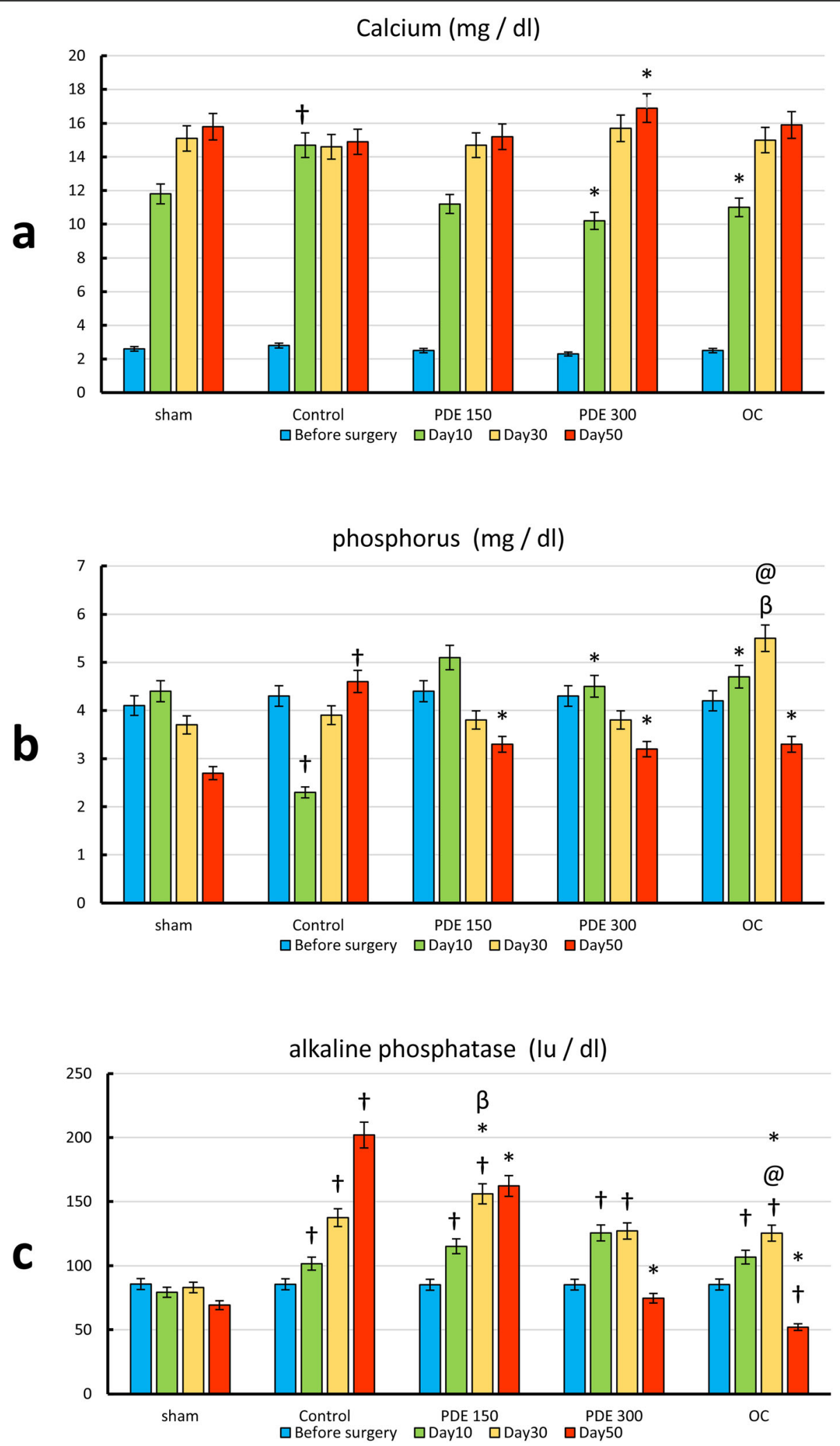

Fig. 1 Levels of calcium, phosphorus, and alkaline phosphatase in experimental groups of the study on days 0, 10, 30, and 50. a Calcium level in the serum. b Phosphorus level in the serum. c The level of alkaline phosphatase. † Significant difference compared to sham group. * Significant difference compared to control group. @ Significant difference compared to group $150 \mathrm{mg}$. $\beta$ Significant difference compared to $300 \mathrm{mg}$ 

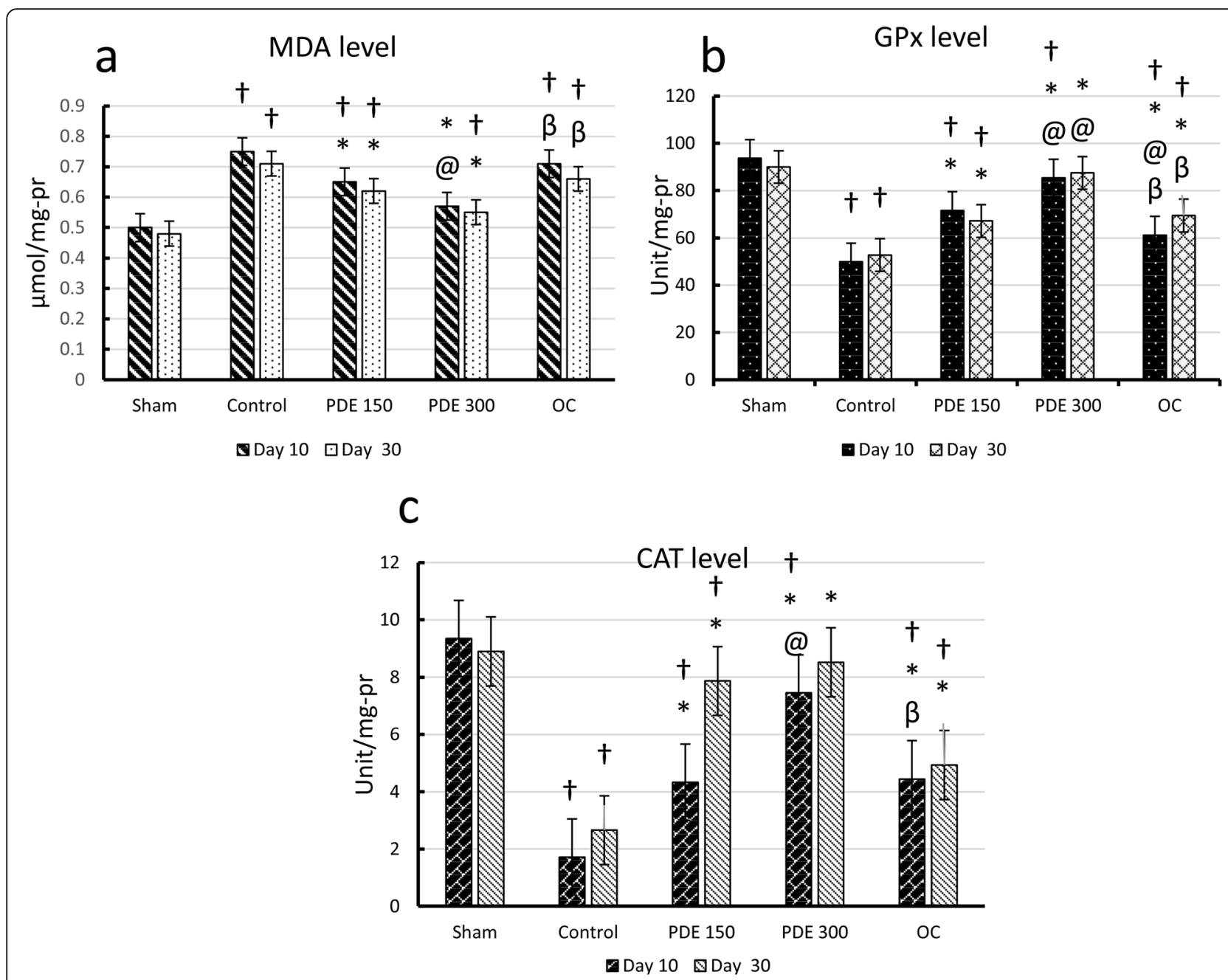

Fig. 2 Oxidative stress biomarkers in different study groups on days 10 and 30. a MDA level in the serum. b GPx level in the serum. c CAT level in the serum. † Significant difference compared to sham group. *Significant difference compared to control group. @ Significant difference compared to group $150 \mathrm{mg}$. $\beta$ Significant difference compared to $300 \mathrm{mg}$

osteocytes' presence were more notable in the PDE 300 group than that in the other groups.

The results of the correlational analysis of histopathological parameters are summarized in Table 3. The difference between the treatment groups and the control group for all measured parameters were significant except for the inflammatory cells $(P<0.05)$. Treatment with PDE 300 remarkably increased osteoblasts/osteocytes and lamellar bone and diminished woven bone compared to the PDE 150 group $(P<0.05)$. PDE 300 group significantly increased Osteoblasts/Osteocytes in comparison to the OC group $(P<0.05)$.

\section{Immunohistochemical findings}

Figure 5 represents the immunohistochemical stained slides of the osteocalcin in different study groups on day 50 following the euthanizing of animals. Figure 5a shows the control group which did not receive any treatment and osteocalcin marker was highly expressed owing to the activity of the osteoblasts and bone formation on day 50. In other treatment groups, the osteocalcin expression was remarkably lower than that in the control group, showing that the bone formation in the treatment groups was approximately completed on day 50 (Fig. 5b-d).

\section{Discussion}

Bone tissue is made of a matrix of collagen fibers and metabolically active cells. Once the bone is fractured or injured, the healing process is commenced by different mechanisms such as biochemical, biomechanical, cellular, hormonal, and pathological mechanisms [15]. Inflammatory, repair, and remodeling stages are known to be the regenerative pattern of bone healing. These stages are influenced by a variety of systemic and local factors [16]. Parathyroid hormone, vitamin D, and calcitonin 


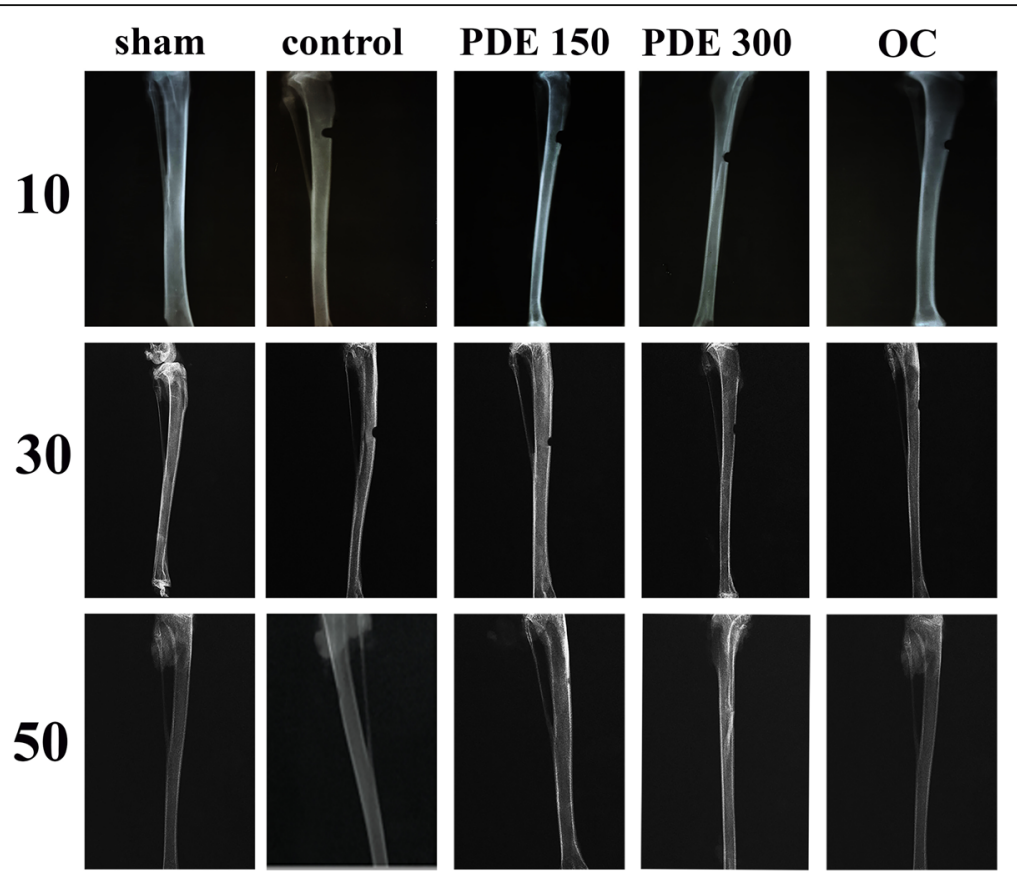

Fig. 3 Radiographs of the tibial bone on days 10, 30, and 50 in different experimental study groups

play a major role in the systemic regulation of bone remodeling by controlling the levels of serum calcium and alkaline phosphate $[16,17]$. Although bone healing is a physiological and spontaneous process, intervention and creating the ideal conditions can be useful for a rapid return to normal function and regeneration [18]. Various methods have been employed in previous studies to speed up the healing process, including electrical stimulation [18], pulsed ultrasound [19], and bone grafts [20]. However, the use of these substances is not economical and not available to the public and requires advanced hospital facilities. Hence, several studies have been performed in bone healing using medicinal plants [6].

Several previous studies have investigated the bone healing process using biochemical markers of the bone

Table 2 Comparison of median of radiographic scores (modified Lane and Sandhu) in different study groups on days 10,30 , and 50

\begin{tabular}{llll}
\hline Groups & Days & & \\
\cline { 2 - 4 } & $\begin{array}{l}\mathbf{1 0} \\
\text { MEDIAN } \\
\text { (MIN-MAX) }\end{array}$ & $\begin{array}{l}\mathbf{3 0} \\
\text { MEDIAN } \\
\text { (MIN-MAX) }\end{array}$ & $\begin{array}{l}\mathbf{5 0} \text { MEDIAN } \\
\text { (MIN-MAX) }\end{array}$ \\
\hline Control & $0(0-0)^{a}$ & $1(0-1)^{b}$ & $3(1-3)^{f}$ \\
Sham & $4(4-4)$ & $4(4-4)$ & $4(4-4)$ \\
PDE 150 & $0(0-0.5)^{a}$ & $2(1-2)^{c}$ & $3(3-4)^{f}$ \\
PDE 300 & $0(0-1)^{a}$ & $3(1-3)^{d}$ & $4(3-4)^{f}$ \\
OC & $0(0-1)^{a}$ & $3(2-3)^{e}$ & $4(3-4)^{f}$ \\
\hline
\end{tabular}

Data are represented as median (min-max). Different letters in each column indicate a significant difference with the control group $(P<0.05)$ formation such as calcium, phosphorus, and alkaline phosphatase [6, 21-24]. High levels of calcium and phosphorus in the blood and extracellular fluids trigger the deposition of calcium phosphate crystals in the osteoid and make it harder [25]. The results of serum calcium in rabbits, on day 10 , in the treatment groups revealed a small decrease in serum calcium levels, which coincided with increased blood phosphorus levels, indicating that calcium was being transferred from the blood to the bone. The tibial lesion stimulated the thyroid to secrete calcitonin and deliver more calcium to the site of fracture. Furthermore, following the consumption of Prunus dulcis extract, this reduction is more noticeable, which is maybe due to the thyroid reaction to the increment in blood calcium levels [25]. These findings are in agreement with the results of the Florence et al. (2017) study [21]. In another research on treatment by oral supplementation of pomegranate peel extract in a mandibular bone defect in a rabbit, on day 7 post-surgery, the level of calcium decreased [22]. A previous study has reported that the level of blood calcium increases following an increment in the dosage of the Arjuna Terminalia extract, and repair occurs more rapidly in the group with a higher dose of extract. This indicates that blood calcium increment causes more calcium-phosphate crystals to deposit at the fracture site, and repair occurs faster [25]. These results are consistent with those of our study, which suggests that increasing the dosage of the PD extract leads to faster healing in the tibial lesion. 


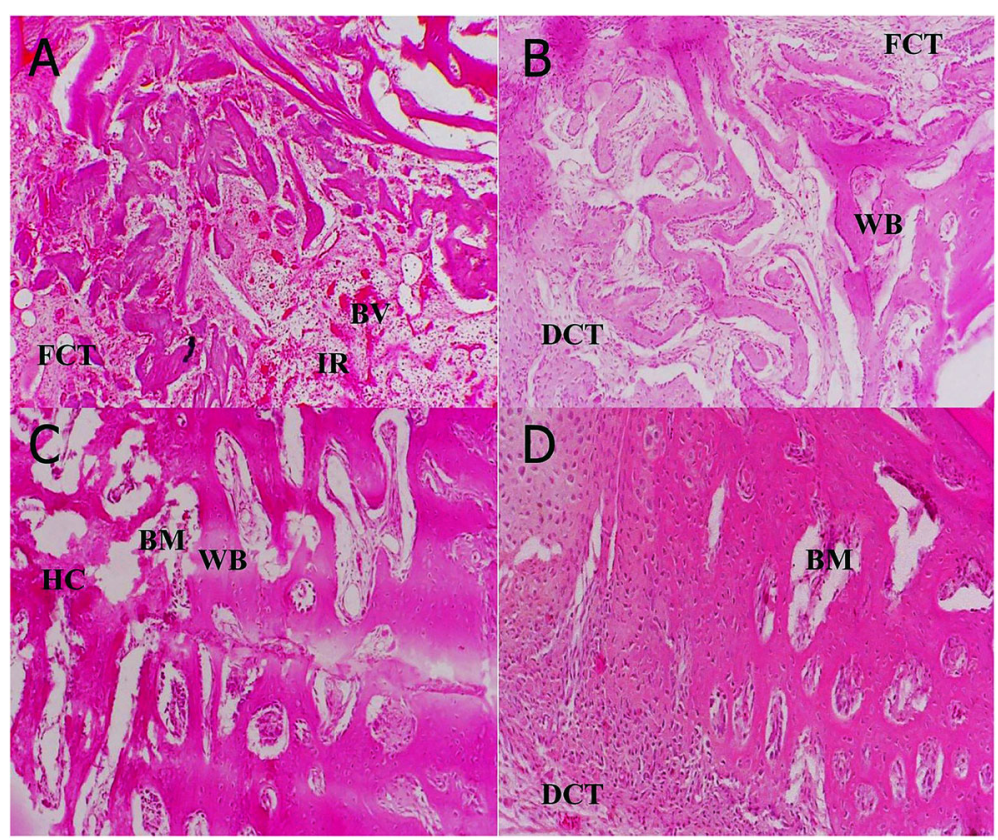

Fig. 4 Hematoxylin and eosin (H\&E) stained slides of tibial bone tissue for histopathological evaluation (H\&E $\times 100)$. A Control group, B PDE 150 group, C osteocare group, D PDE 300 group. BM: bone marrow, FCT: fibrous connective tissue, DCT: dense connective tissue, IR: inflammatory reaction, HC: hyaline cartilage, $\mathrm{BV}$ : blood vessels, WB: woven bone

Phosphorus is an essential bone component and is necessary for proper skeletal mineralization. Most of the body's phosphorus is stored in the bones [26]. Blood phosphorus is initially increased following bone fracture due to necrosis and destruction of bone cells at the fracture site, where the stored phosphorus is released into the blood. Several days after the beginning of the bone healing process, the level of phosphorus in the blood decreases due to the increase in the blood calcium level. Blood phosphorus level is inversely proportional to the calcium [25]. Herein phosphorus serum level in the treatment groups has increased on day 10 after surgery, but in the control group, it was increased on days 30 and 50 post-surgery. It seems that the presence of phosphorus in the Prunus dulcis extract accelerates the healing process of bone. Besides, hydroxyapatite crystals in bone are formed by the deposition of phosphorus and calcium in the callus. Therefore, the high amount of phosphorus in the extract speeds up the formation of hydroxyapatite crystals and faster bone healing [21]. In the present study, a faster reduction in the amount of phosphorus was observed in the PDE 300 group compared to the other treatment groups. This can indicate faster hydroxyapatite deposition at the site of bone

Table 3 Histopathological parameters in different experimental groups of the study

\begin{tabular}{lllll}
\hline Parameter & Groups & & & \\
\cline { 2 - 4 } & Control & PDE 150 & PDE 300 & OC \\
\hline Fibroblasts/Fibrocytes & $122.5 \pm 10.54$ & $51.33 \pm 3.06^{*}$ & $53.67 \pm 1.53^{*}$ & $48.33 \pm 3.79^{*}$ \\
Chondroblasts/Chondrocytes & $11.33 \pm 3.06$ & $59.33 \pm 4.61^{*}$ & $57.67 \pm 14.43^{*}$ & $59.33 \pm 3.78^{*}$ \\
Osteoblasts/Osteocytes & $2.33 \pm 1.52$ & $42.33 \pm 0.57^{*}$ & $46.66 \pm 1.15^{*}, *^{* *}$ & $42 \pm 1^{*}, *^{* * *}$ \\
Osteoclast & 0.0 & $1.66 \pm 0.57^{*}$ & $1.33 \pm 0.57^{*}$ & $0.66 \pm 0.57$ \\
Inflammatory cells & $13.66 \pm 0.57$ & $10 \pm 4.58$ & $7.33 \pm 5.03$ & $12.33 \pm 1.52$ \\
Vessels & $18 \pm 1$ & $12.33 \pm 1.52^{*}$ & $11 \pm 1.73^{*}$ & $12.66 \pm 2.08^{*}$ \\
Woven bone & $34.67 \pm 1.64$ & $28 \pm 1.73^{*}$ & $20.67 \pm 1.53^{*}, *^{*}$ & $24 \pm 5.29^{*}$ \\
Lamellar bone & $6.33 \pm 2.3$ & $14.33 \pm 2.51^{*}$ & $22 \pm 2^{*}, *^{* *}$ & $17 \pm 6.24^{*}$ \\
\hline
\end{tabular}

${ }_{* * *}^{p}<0.05$ compared with the control group

$p<0.05$ compared with the PDE 150 group

${ }^{* * *} p<0.05$ compared with the PDE 300 group 


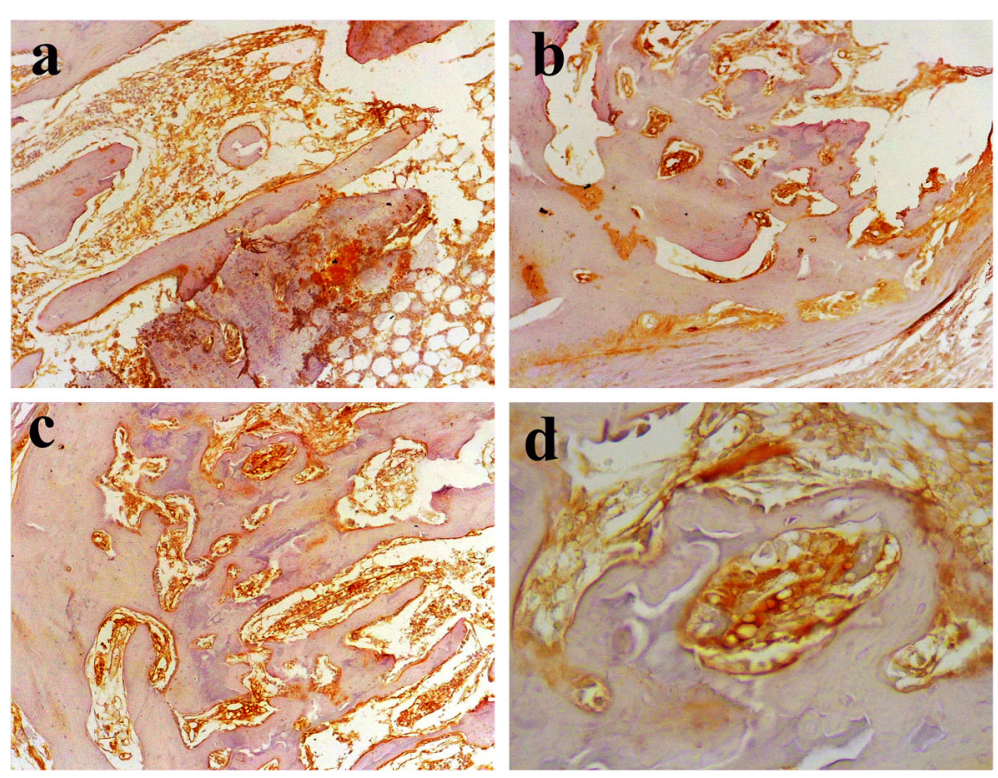

Fig. 5 Immunohistochemical stained slides of osteocalcin protein. a Control group, b PDE 150 group, c PDE 300 group, d Osteocare group

damage. These findings are in accordance with the previous report by Florence et al. (2017), which showed that P. pellucida ethanolic extract dose-dependently increased mineral deposition [21].

Alkaline phosphatase is an indicator of liver damage or any systemic inflammatory reaction [27]. Alkaline phosphatase is secreted by osteoblasts and plays an important role in bone healing. This enzyme triggers the mineralization of the osteoid by increasing the local concentration of calcium phosphate. Alkaline phosphatase is an indicator for bone formation, and higher serum level of this enzyme shows faster maturation and more activity of osteoblasts [28]. The higher alkaline phosphatase levels in the PDE 300 group and the osteocare group 10 days after surgery indicate greater osteoblast activity, and faster healing.

Shuid et al. (2011) investigated the effect of $\alpha$ Tocopherol on osteoporotic fracture healing in early stages and concluded that the group treated by $\alpha-$ Tocopherol revealed a significant decrease in the TBARS level and increased the GPx and SOD levels in comparison to the sham group [29]. Effect of tricalcium phosphate/collagen (TCP/Collagen) nanocomposite scaffold on bone healing in a rabbit model was examined by Farahi et al. (2019), and oxidative stress evaluation in the plasma indicated that in the treatment group level of MDA significantly reduced compared to the sham group. SOD and GPx levels significantly increased in the treatment group in comparison to the sham group [27]. In a study conducted by Jia et al. (2006), effects of Almond (Prunus dulcis) consumption in the smokers was assessed, and oxidative stress biomarkers including
MDA, GPx, and SOD in the plasma were evaluated. In the almond group, the amount of MDA significantly reduced, and levels of GPx and SOD increased, but it was not significant [30]. Another research investigated the protective effects of almond oil on hepatic damage due to carbon tetrachloride. In this research, oxidative stress biomarkers such as SOD, CAT, GPx, and MDA were examined. The authors found that in the treatment group with the higher dosage of almond oil, SOD and CAT significantly increased in comparison to the control group. Moreover, GPx level increased, and MDA level reduced, but the difference was not significant. In agreement with previous studies, in this research, treatment with Prunus dulcis extract remarkably reduced MDA level and increased GPx and CAT levels compared to the control group that did not receive any treatment.

In the present study, a comparison of radiographic scores according to the modified Lane and Sandhu method in different study groups on days 10 and 50 showed no significant difference between the treatment groups and the control group. However, on day 30 treatment groups remarkably increased the radiographic score compared to the control group. Oryan et al. (2012) assessed the effects of combined hydroxyapatite and human platelet-rich plasma on radius bone healing in a rabbit. The radiological evaluation based on the modified Lane and Sandhu scoring method revealed that on days 14 and 28 there was no significant difference between the treatment groups and the control group. However, on days 42 and 56, the score in the treatment group was significantly higher than that in the control group [31]. These results are in line with those of our study and 
suggest that on the 10 first days, treatments do not influence the radiographic scores.

Matos et al. (2008) evaluated the histomorphological parameters of bone healing in a rabbit fibular osteotomy. According to this research, bone healing possesses three histopathological phases. The first stage continues until day 10 , and inflammatory cytokines induce intensive cell multiplication in this stage. Two weeks following the fracture, the second phase is commenced with converting the woven bones to the lamellar bone. Eventually, the third stage occurs on day 21 , and cartilage and woven bone can be observed around the callus as an evidence of this stage [32]. Matos et al. (2008), in this research, evaluated the percentage of woven and lamellar bone in the first, second, and fourth week during fracture healing and concluded that the percentage of woven bone in the first week was significantly higher than the lamellar bone and in the fourth week, the percentage of lamellar bone notably increased compared to the woven bone [32]. In accordance with previous results, in the present research on day 50, a significant increase in the numbers of chondroblasts/chondrocytes, osteoblasts/osteocytes, and lamellar bone was observed in the treatment groups in comparison to the control group. Among treatment groups, the PDE 300 group significantly increased the number of osteoblasts/osteocytes compared to the OC group.

Wang et al. (2009) in a research examined the effects of VEGF on osteogenesis following shockwave-promoted fracture healing in rabbits and concluded that osteocalcin expression after 56 days was significantly higher in the control group than that in the treated group [33]. In accordance with the previous results, the present study demonstrated that the treatment groups significantly reduced the osteocalcin expression compared to the control group on day 50 . This result may be explained by the fact that in the control group on day 50 the healing process is in progress and osteoblasts are active but in the treatment groups particularly in the PDE 300 and the $\mathrm{OC}$ group, bone regeneration is approximately complete on day 50 .

\section{Conclusion}

The main goal of the current study was to determine the treatment effects of aqueous extract of Prunus dulcis on bone healing in the rabbit. The beneficial effects of the extract on blood biochemical parameters, radiological assessments, histological, and IHC evaluations may be owing to the mineral composition of the extract and the antioxidant effects, as suggested by the assessment of oxidative stress biomarkers. The major limitation of this study is that the molecular detection of bone healing biomarkers was not assessed.

\section{Abbreviations}

MDA: Malondialdehyde; GPx: Glutathione peroxidase; CAT: Catalase; IHC: Immunohistochemistry; PDE: Prunus dulcis extract; OC: Osteocare

\section{Acknowledgements}

The present study is derived from the DVM thesis of Nima Anaraki and Amir Hosein Beiraghi performed at Lorestan University. The authors want to thank the vice-chancellor of research of Lorestan University.

\section{Authors' contributions}

$\mathrm{NA}$ and $\mathrm{AHB}$ : drafting the manuscript, analysis and interpretation of the data, conception and design of the work, investigation, editing, and revising the manuscript. AR: drafting the manuscript, copyediting, revising the final version and final approval of the version to be published, conception and design of the work, and methodology. FD: investigation, acquisition and interpretation of the data, preparing figures and tables, editing, and revising the manuscript. GHFK: conception and design of the work, and investigation. ABS: methodology and validation of data. All authors read and approved the final manuscript.

\section{Funding}

This work was funded by the Lorestan University with a grant number of (LU-911590032004-2018).

\section{Availability of data and materials}

All data generated or analyzed during this study are included in this published article.

\section{Declarations}

\section{Ethics approval and consent to participate}

This study was carried out at Lorestan University and was approved by the Animal Ethics Committee of the Faculty of Veterinary Medicine, Lorestan University.

\section{Consent for publication}

Not applicable.

\section{Competing interests}

The authors declare that they have no competing interests.

\section{Author details}

${ }^{1}$ Department of Clinical Sciences, Faculty of Veterinary Medicine, Lorestan University, Khorramabad, Iran. ${ }^{2}$ Department of Surgery and Diagnostic Imaging, Faculty of Veterinary Medicine, Urmia University, Urmia, Iran. ${ }^{3}$ Department of Pathobiology, Faculty of Veterinary Medicine, Lorestan University, Khorramabad, Iran. ${ }^{4}$ Department of Veterinary Surgery and Radiology, School of Veterinary Medicine, Shiraz University, Shiraz, Iran.

Received: 18 December 2020 Accepted: 23 May 2021

Published online: 07 June 2021

\section{References}

1. Costa-Pinto AR, Reis RL, Neves NM. Scaffolds based bone tissue engineering: the role of chitosan. Tissue Eng Part B Rev. 2011;17(5):331-47 https://doi. org/10.1089/ten.teb.2010.0704.

2. Gómez-Barrena E, Rosset P, Lozano D, Stanovici J, Ermthaller C, Gerbhard F. Bone fracture healing: cell therapy in delayed unions and nonunions. Bone. 2015;70:93-101 https://doi.org/10.1016/j.bone.2014.07.033.

3. Amini AR, Laurencin CT, Nukavarapu SP. Bone tissue engineering: recent advances and challenges. Crit Rev Biomed Eng. 2012;40(5) https://doi.org/1 0.1615/CritRevBiomedEng.v40.i5.10.

4. Giannotti S, Trombi L, Bottai V, Ghilardi M, D'Alessandro D, Danti S, et al. Use of autologous human mesenchymal stromal cell/fibrin clot constructs in upper limb non-unions: long-term assessment. PLoS One. 2013;8(8):e73893. https://doi.org/10.1371/journal.pone.0073893.

5. Remedios A. Bone and bone healing. Vet Clin North Am Small Anim. 1999; 29(5):1029-44. https://doi.org/10.1016/S0195-5616(99)50101-0.

6. Adhikari S, Gurung TM, Koirala A, Adhikari BR, Gurung R, Basnet S, et al. Study on fracture healing activity of ethnomedicinal plants in western Nepal. World J Pharm Pharm Sci. 2017;6(10):93-102. 
7. Davoodi F, Taheri S, Raisi A, Rajabzadeh A, Ahmadvand H, Hablolvarid MH, et al. Investigating the sperm parameters, oxidative stress and histopathological effects of salvia miltiorrhiza hydroalcoholic extract in the prevention of testicular ischemia reperfusion damage in rats. Theriogenology. 2020;144:98-106 https://doi.org/10.1016/j.theriogenology.2 020.01.002.

8. Akerele O. Summary of WHO guidelines for the assessment of herbal medicines. Herbal Gram. 1993:28(13):13-9.

9. Kahlaoui M, Borotto Dalla Vecchia S, Giovine F, Ben Haj Kbaier H, Bouzouita $\mathrm{N}$, Barbosa Pereira L, et al. Characterization of polyphenolic compounds extracted from different varieties of Almond Hulls (Prunus dulcis L.). Antioxidants. 2019;8(12):647 https://doi.org/10.3390/antiox8120647.

10. Prgomet I, Gonçalves B, Domínguez-Perles R, Pascual-Seva N, Barros Al. Valorization challenges to almond residues: phytochemical composition and functional application. Molecules. 2017;22(10):1774 https://doi.org/10.3390/ molecules22101774.

11. Barreca D, Nabavi SM, Sureda A, Rasekhian M, Raciti R, Silva AS, et al. Almonds (Prunus Dulcis Mill. DA Webb): a source of nutrients and healthpromoting compounds. Nutrients. 2020;12(3):672 https://doi.org/10.3390/ nu12030672.

12. Bigham-Sadegh A, Karimi I, Alebouye M, Shafie-Sarvestani Z, Oryan A. Evaluation of bone healing in canine tibial defects filled with cortical autograft, commercial-DBM, calf fetal DBM, omentum and omentum-calf fetal DBM. J Vet Sci. 2013;14(3):337-43 https://doi.org/10.4142/jvs.2 013.14.3.337.

13. Lane JM, Sandhu H. Current approaches to experimental bone grafting. Orthop Clin North Am. 1987;18(2):213-25. https://doi.org/10.1016/S00305898(20)30385-0.

14. Verbicaro T, Giovanini AF, Zielak JC, Baratto Filho F, Araujo MR, Deliberador TM. Osteocalcin immunohistochemical expression during repair of criticalsized bone defects treated with subcutaneous adipose tissue in rat and rabbit animal model. Braz Dent J. 2013;24(6):559-64 https://doi.org/10.1590/ 0103-6440201302362.

15. Kalfas $\mid H$. Principles of bone healing. Neurosurg Focus. 2001;10(4):1-4 https://doi.org/10.3171/foc.2001.10.4.2.

16. Raisz LG. Physiology and pathophysiology of bone remodeling. Clin Chem. 1999;45(8):1353-8 https://doi.org/10.1093/clinchem/45.8.1353.

17. Bilezikian JP, Raisz LG, Martin TJ. Principles of bone biology. Cambridge: Academic press; 2008.

18. Gorustovich A, Rosenbusch M, Guglielmotti MB. Characterization of bone around titanium implants and bioactive glass particles: an experimental study in rats. Int J Oral Maxillofac Implants. 2002;17(5):644.

19. Hadjiargyrou M, McLeod K, Ryaby JP, Rubin C. Enhancement of fracture healing by low intensity ultrasound. Clin Orthop Relat Res (1976-2007). 1998;355:S216

20. Rumi MN, Deol GS, Singapuri KP, Pellegrini VD Jr. The origin of osteoprogenitor cells responsible for heterotopic ossification following hip surgery: an animal model in the rabbit. J Orthop Res. 2005;23(1):34-40 https://doi.org/10.1016/j.orthres.2004.05.003.

21. Florence NT, Huguette STS, Hubert DJ, Raceline GK, Desire DDP, Pierre K, et al. Aqueous extract of Peperomia pellucida (L.) HBK accelerates fracture healing in Wistar rats. BMC Compl Alternative Med. 2017;17(1):188 https:// doi.org/10.1186/s12906-017-1686-3.

22. Omer RM, Baban DA, Ahmed BM. Effect of oral supplementation for rabbits of pomegranate seed extract on some serum biochemical parameters in relation to oral inflammation, oxidative stress, and wound healing. JBCD. 2019;31(2):14-9. https://doi.org/10.26477/jbcd.v31i2.2618.

23. Ibrahim MRM, Singh S, Merican AM, Raghavendran HRB, Murali MR, Naveen SV, et al. The effect of strontium ranelate on the healing of a fractured ulna with bone gap in rabbit. BMC Vet Res. 2016;12(1):1-9 https://doi.org/10.11 86/s12917-016-0724-6.

24. Neto VFP, Ribeiro RM, Morais CS, Campos MB, Vieira DA, Guerra PC, et al. Chenopodium ambrosioides as a bone graft substitute in rabbits radius fracture. BMC Compl Alternative Med. 2017;17(1):350 https://doi.org/10.11 86/s12906-017-1862-5.

25. Giri R, Giri K, Palandurkar M. Use of biochemical parameters in radiologically proved fracture healing property of Arjuna Terminalia, in rats. Res J Pharm, Biol Chem Sci. 2015:6(4):336-43.

26. Palacios $C$. The role of nutrients in bone health, from A to Z. Crit Rev Food Sci Nutr. 2006:46(8):621-8 https://doi.org/10.1080/10408390500466174.
27. Farahi H, Mashhadi-Rafie S, Jahandideh A, Asghari A, Shirazi-Beheshtiha SH. Evaluation of possible beneficial effect of tricalcium phosphate/collagen (TCP/Collagen) nanocomposite scaffold on bone healing in rabbits: biochemical assessments. IJVS. 2019;14(2):162-72 https://doi.org/10.22034/ IVSA.2019.193769.1189.

28. Paskalev MD. Time course of serum malondialdehyde concentrations as a marker of oxidative stress in experimental canine osteotomies fixed by two different techniques. Comp Clin Pathol. 2009;18(3):265-8 https://doi.org/10.1 007/s00580-008-0796-1.

29. Shuid AN, Mohamad S, Muhammad N, Fadzilah FM, Mokhtar SA, Mohamed $\mathrm{N}$, et al. Effects of a-tocopherol on the early phase of osteoporotic fracture healing. J Orthop Res. 2011;29(11):1732-8 https://doi.org/10.1002/jor.21452.

30. Jia X, Li N, Zhang W, Zhang X, Lapsley K, Huang G, et al. A pilot study on the effects of almond consumption on DNA damage and oxidative stress in smokers. Nutr Cancer. 2006;54(2):179-83 https://doi.org/10.1207/s15327914 nc5402_4.

31. Oryan A, Parizi AM, Shafiei-Sarvestani Z, Bigham A. Effects of combined hydroxyapatite and human platelet rich plasma on bone healing in rabbit model: radiological, macroscopical, hidtopathological and biomechanical evaluation. Cell Tissue Bank. 2012;13(4):639-51 https://doi.org/10.1007/s1 0561-011-9285-X.

32. Matos MA, Araújo FP, Paixão FB. Histomorphometric evaluation of bone healing in rabbit fibular osteotomy model without fixation. J Orthop Surg Res. 2008;3(1):4 https://doi.org/10.1186/1749-799X-3-4.

33. Wang C-J, Huang K-E, Sun Y-C, Yang Y-J, Ko J-Y, Weng L-H, et al. VEGF modulates angiogenesis and osteogenesis in shockwave-promoted fracture healing in rabbits. J Surg Res. 2011;171(1):114-9 https://doi.org/10.1016/j. jss.2010.01.045.

\section{Publisher's Note}

Springer Nature remains neutral with regard to jurisdictional claims in published maps and institutional affiliations.

Ready to submit your research? Choose BMC and benefit from:

- fast, convenient online submission

- thorough peer review by experienced researchers in your field

- rapid publication on acceptance

- support for research data, including large and complex data types

- gold Open Access which fosters wider collaboration and increased citations

- maximum visibility for your research: over $100 \mathrm{M}$ website views per year

At BMC, research is always in progress.

Learn more biomedcentral.com/submissions 